\title{
Altered CSF Albumin Quotient Links Peripheral Inflammation and Brain Damage in MS
}

Marco Puthenparampil, MD, PhD, Paula Tomas-Ojer, Thorsten Hornemann, PhD, Andreas Lutterotti, MD, Ilijas Jelcic, MD, PhD, Mario Ziegler, Andreas J. Hülsmeier, PhD, Carolina Cruciani, PhD, Wolfgang Faigle, PhD, Roland Martin, MD, PhD, and Mireia Sospedra, PhD

Neurol Neuroimmunol Neuroinflamm 2021;8:e951. doi:10.1212/NXI.0000000000000951

\author{
Correspondence \\ Dr. Sospedra \\ Mireia.SospedraRamos@usz.ch
}

\begin{abstract}
\section{Objective}

CNS damage can increase the susceptibility of the blood-brain barrier (BBB) to changes induced by systemic inflammation. The aim of this study is to better understand BBB permeability in patients with MS and to examine whether compromised BBB integrity in some of these patients is associated with CNS damage and systemic inflammation.
\end{abstract}

\section{Methods}

Routine CSF measurements of 121 patients with MS were analyzed including number and type of infiltrating cells, total protein, lactate, and oligoclonal bands, as well as intrathecal production of immunoglobulins and CSF/serum quotients for albumin, immunoglobulins, and glucose. In addition, in a subcohort of these patients, we performed ex vivo immunophenotyping of CSFinfiltrating and paired circulating lymphocytes using a panel of 13 monoclonal antibodies, we quantified intrathecal neurofilament light chain (NF-L) and chitinase 3-like 1 (CHI3L1), and we performed intrathecal lipidomic analysis.

\section{Results}

Patients with MS with abnormal high levels of albumin in the CSF showed a distinct CSF cell infiltrate and markers of CNS damage such as increased intrathecal levels of NF-L and CHI3L1 as well as a distinct CSF lipidomic profile. In addition, these patients showed higher numbers of circulating proinflammatory Th1 and Th $1^{*}$ cells compatible with systemic inflammation. Of interest, the abnormally high levels of albumin in the CSF of those patients were preserved over time.

\section{Conclusions}

Our results support the hypothesis that CNS damage may increase BBB vulnerability to systemic inflammation in a subset of patients and thus contribute to disease heterogeneity. 


\section{Glossary}

BBB = blood-brain barrier; CHI3L1 = chitinase 3-like 1; FADS3 = fatty acid desaturase 3; HLA = human leukocyte antigen; IFN = interferon; Ig = immunoglobulin; NF-L = neurofilament light chain; OIND = other inflammatory neurologic diseases; ONIND = other noninflammatory neurologic diseases; PC = phosphatidylcholine; $\mathbf{Q A l b}=$ serum albumin quotient; $\mathbf{Q N o r m}=$ normal QAlb; $\mathbf{R B C}=$ red blood cell; SAdienine = sphingadienine; $\mathbf{S M}=$ sphingomyelin .

\section{Role of Central Nervous System Damage and Systemic Inflammation in Blood Brain Barrier Integrity in Multiple Sclerosis}

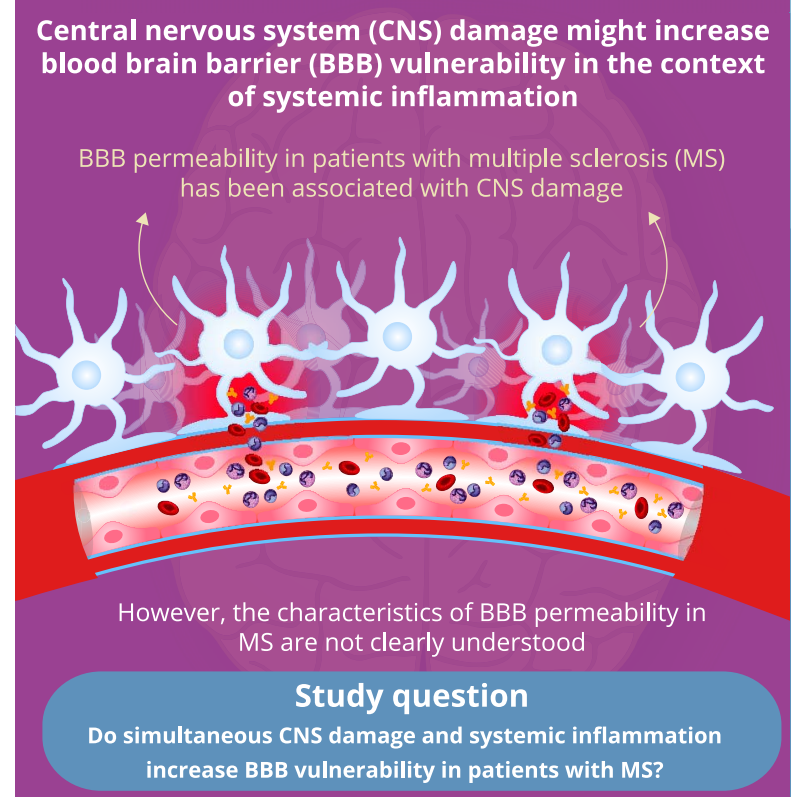

doi:10.1212/NXI.0000000000000951

Copyright (c) 2020 American Academy of Neurology

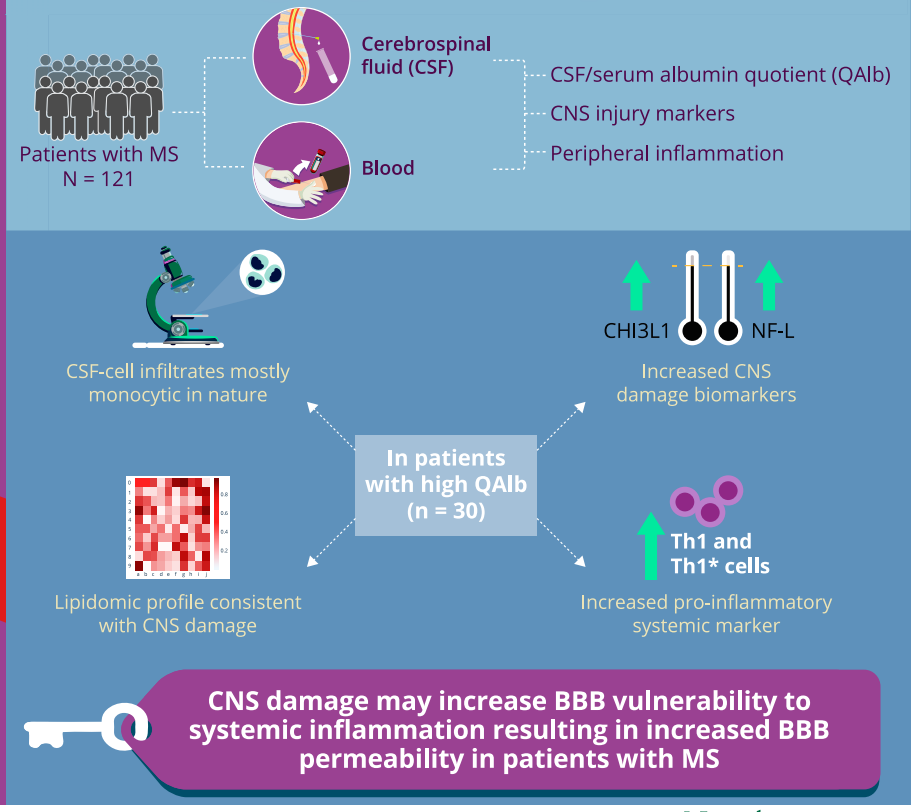

Neurology

Neuroimmunology \& Neuroinflammation
Systemic inflammation can influence blood-brain barrier (BBB) permeability and increase vesicular trafficking of albumin from serum to the CNS. ${ }^{1}$ In animal models of Alzheimer disease, ${ }^{2}$ ischemic stroke, ${ }^{3}$ and $M S,{ }^{4,5}$ it has been observed that the effect of systemic inflammation on $\mathrm{BBB}$ permeability was higher in animals with these CNS pathologies, suggesting that brain damage could increase the susceptibility of the $\mathrm{BBB}$ to changes induced by systemic inflammation. Consistent with these findings, a human study demonstrated a link between markers of systemic inflammation and markers of increased BBB permeability, in particular high CSF/serum albumin quotient (QAlb) in individuals with abnormal CSF measures but not in those without. Because abnormal CSF measures most likely reflect CNS alterations, these results support a role of CNS damage in increasing BBB susceptibility to systemic inflammation. ${ }^{6}$

MS is a heterogeneous immune-mediated neurologic disease that damages the CNS. This damage might increase the susceptibility of the BBB to changes induced by a systemic inflammation in some patients and contribute to MS heterogeneity. Supporting such an association between CNS damage and changes in BBB permeability, it has been observed that high QAlb and other CSF markers of compromised BBB integrity in patients with MS are accompanied by brain atrophy and faster increase in disability. ${ }^{7,8}$

To better understand BBB permeability in MS and its putative association with CNS damage and systemic inflammation, we performed a detailed characterization of CSF and paired blood samples that included immunophenotyping and lipidomics.

\section{Methods}

\section{Patient Material}

Paired CSF and blood samples were collected from 121 untreated patients with MS (20 patients with radiologically or clinically isolated syndrome, 91 with relapsing-remitting MS, and 10 with progressive MS), 40 controls with other noninflammatory neurologic diseases (ONIND), and 21 with other inflammatory neurologic diseases (OIND). All CSF samples were obtained for diagnostic purposes. Demographic 
Table 1 Demographic and Clinical Features of Patients With MS and Controls

\begin{tabular}{|c|c|c|c|c|c|}
\hline & \multicolumn{3}{|l|}{ MS cohort } & \multicolumn{2}{|l|}{ Controls } \\
\hline & Main & Sub-1 & Sub-2 & ONIND & OIND \\
\hline No. of patients & 121 & 79 & 36 & 40 & 21 \\
\hline Female/male ratio & 2.02 & 2.16 & 2.3 & 0.72 & 0.72 \\
\hline Age $(y)$ & $35.9 \pm 9.9$ & $35.9 \pm 10.2$ & $37.5 \pm 11.4$ & $40.7 \pm 12.6$ & $45.2 \pm 9.5$ \\
\hline \multirow[t]{3}{*}{ Disease duration (mo) } & $25.5 \pm 48.3$ & $26 \pm 51.7$ & $29.4 \pm 55.1$ & & \\
\hline & & \multicolumn{4}{|l|}{ MS main cohort } \\
\hline & & With increased QAlb & & Without increased QAlb & $p$ Value \\
\hline No. of patients & & 30 & & 91 & \\
\hline Female/male ratio & & 1.1 & & 2.5 & \\
\hline Age at CSF puncture (y) & & $35.2 \pm 10.2$ & & $36.6 \pm 10$ & ns \\
\hline Age at onset (y) & & $32.1 \pm 8.3$ & & $34.4 \pm 9.8$ & ns \\
\hline RIS/CIS (\%) & & 33.4 & & 40 & \\
\hline RRMS (\%) & & 56.6 & & 53.7 & \\
\hline PMS (\%) & & 10 & & 6.3 & \\
\hline Disease duration (mo) & & $27.6 \pm 49.2$ & & $26.5 \pm 48.3$ & ns \\
\hline Time since last relapse (d) & & $119.3 \pm 317.7$ & & $287.8 \pm 642.5$ & \\
\hline Clinically active ${ }^{a}(\%)$ & & 73.3 & & 54.9 & \\
\hline Gd contrast-enhancing lesions ${ }^{\mathrm{a}}(\%)$ & & 60 & & 48.7 & \\
\hline Lesions location & & & & & \\
\hline Optic neuritis (\%) & & 28.6 & & 18.6 & \\
\hline Myelitis (\%) & & 25 & & 19.7 & \\
\hline Brainstem (\%) & & 7.1 & & 8.1 & \\
\hline Several (\%) & & 39.3 & & 53.6 & \\
\hline Expanded Disability Status Scale & & $2.25 \pm 1.8$ & & $1.7 \pm 1.5$ & \\
\hline HLADR15 (\%) & & 41.3 & & 50.5 & \\
\hline CSF & & & & & \\
\hline CSF OCB type II (\%) & & 90 & & 81 & \\
\hline Albumin quotient & & $7.94 \pm 1.03$ & & $4.24 \pm 1.81$ & $<0.0001$ \\
\hline IgA index & & $0.37 \pm 0.36$ & & $0.32 \pm 0.27$ & ns \\
\hline IgG index & & $0.79 \pm 0.38$ & & $1.11 \pm 0.87$ & ns \\
\hline IgM index & & $0.14 \pm 0.21$ & & $0.16 \pm 0.16$ & ns \\
\hline Patients with $\lg G(\operatorname{loc})>10 \%(\%)$ & & 35.7 & & 52.9 & \\
\hline Total intrathecal protein $(\mathrm{mg} / \mathrm{L})$ & & $619.0 \pm 159.7$ & & $392.8 \pm 88.88$ & $<0.0001$ \\
\hline Intrathecal lactate (mmol/L) & & $1.64 \pm 0.20$ & & $1.61 \pm 0.25$ & ns \\
\hline Glucose quotient & & $0.65 \pm 0.09$ & & $0.66 \pm 0.11$ & ns \\
\hline Albumin in serum (g/L) & & $46.08 \pm 3.57$ & & $45.63 \pm 5.03$ & ns \\
\hline $\begin{array}{l}\text { Abbreviations: CIS = clinically isolate } \\
\text { other noninflammatory neurologic } \\
\text { syndrome; RRMS = relapsing-remitt } \\
\text { Mean } \pm \text { SD is shown. } \\
\text { a Clinically active means during a rel } \\
\text { of systemic inflammation within } 3 \mathrm{~m}\end{array}$ & $\begin{array}{l}\text { syndrome; } \\
\text { seases; PMS } \\
\text { g MS. } \\
\text { se, i.e., in the } \\
\text { onths before }\end{array}$ & $\begin{array}{l}\text { munoglobulin; OCB = } \\
\text { gressive MS; QAlb = se } \\
\text { ence of new neurologic } \\
\text { er lumbar puncture. }\end{array}$ & $\begin{array}{l}\text { and; OIND } \\
\text { n quotient; } \\
\text { asting at lea }\end{array}$ & $\begin{array}{l}\mathrm{D}=\text { other inflammatory neuro } \\
\mathrm{t} \text {; QNorm = normal QAlb; RIS } \\
\text { east } 24 \text { hours and with no evid }\end{array}$ & $\begin{array}{l}\text {; ONIND = } \\
\text { lly isolated } \\
\text { symptoms }\end{array}$ \\
\hline
\end{tabular}




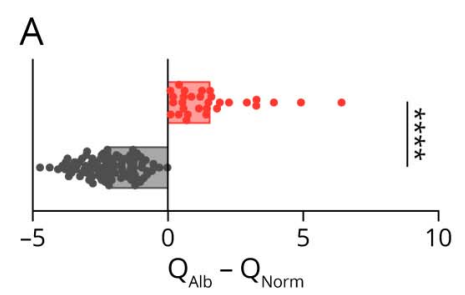

$\mathrm{B}$

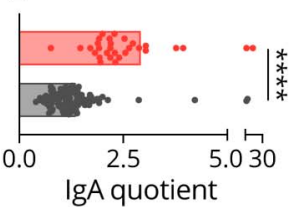

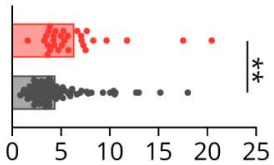
IgGquotient

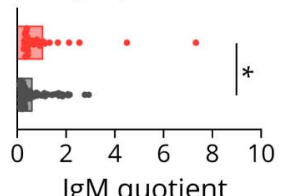

IgM quotient
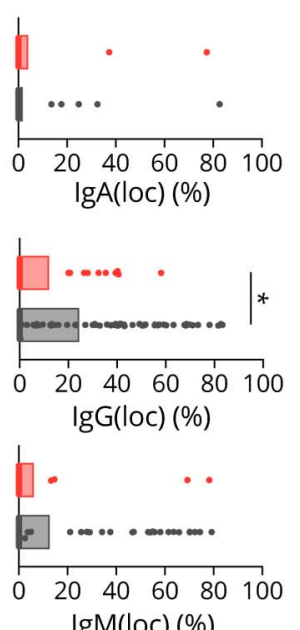

C

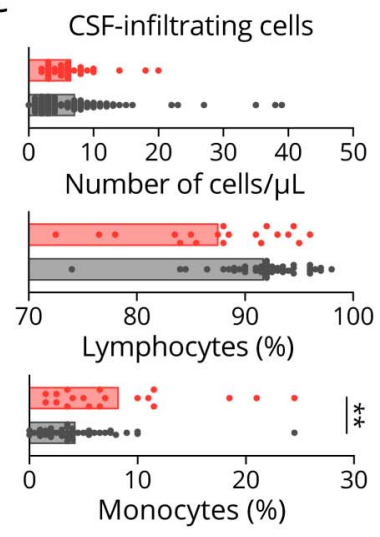

D

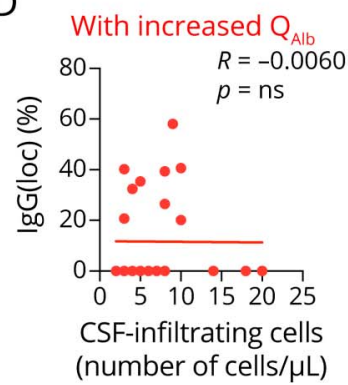

$\square$ With increased $Q_{\text {Alb }}$ $\square$ Without increased $\mathrm{Q}_{\mathrm{Alb}}$

(A) Graph shows $Q_{\text {Alb }}$ minus $Q_{\text {Norm. }}$ Patients in which this difference is positive are showed in red and those in which is negative in black. Comparison between patients with and without increased Qlb $_{\text {of: }}$ (B) quotients and Igs(loc) expressed as percentage (\%) for IgA, IgG, and IgM and (C) CSF-infiltrating cells (number of cells/ $\mu \mathrm{L}$ ) and frequency (\%) of lymphocytes and monocytes analyzed under the microscope. (D) Correlation between number of CSF-infiltrating cells and IgG(loc) expressed as percentage (\%). Graphs (A-D) represent the main cohort of 121 patients with MS. Each dot in the graphs corresponds to 1 patient, and bars show the mean. A $t$ test for normally distributed variables and $U$ test (Mann-Whitney) for non-normally distributed variables was used to compared patients. Linear correlation was tested using Pearson for normally distributed and Spearman $r$ for non-normally distributed variables. Statistical significance $(* p<0.05, * \star p<0.01$, and $* \star \star * p<0.0001)$ is shown. Ig = immunoglobulin; QAlb = serum albumin quotient; QNorm = normal QAlb.

and clinical characteristics are summarized in table 1. Patients were recruited from the Neuroimmunology and MS Research Section, Neurology Clinic, University Hospital Zurich. MS diagnosis was based on the revised McDonald criteria. ${ }^{9}$ Patients who had not received steroids at least 4 weeks before enrollment or any immunomodulatory or immunosuppressive agent during the last 3 months were considered untreated and included in the study. In particular, 97 patients were never treated, 16 patients were previously treated only with steroids, 4 patients received steroids and an immunomodulatory or immunosuppressive agent (1 patient, interferon [IFN] $\beta$-1a; 1 patient, glatiramer acetate; and 2 patients, dimethyl fumarate), and 4 patients received only an immunomodulatory or immunosuppressive agent (1 patient, IFN $\beta-1 \mathrm{a}$; 2 patients, glatiramer acetate; and 1 patient, dimethyl fumarate).

\section{Standard Protocol Approvals, Registrations, and Patient Consents}

The Cantonal Ethics Committee of Zurich approved the study procedures (EC-No. 2013-0001). Informed consent was obtained from all patients or relatives.

\section{Routine CSF and Serum Measures}

CSF-infiltrating cells were counted with a Fuchs Rosenthal counting chamber under the microscope within 1 hour after lumbar puncture. CSF total protein as well as CSF and serum albumin, immunoglobulin (Ig) G, IgM, and IgA were determined by immunonephelometry. Quotients $(\mathrm{Q})$ were defined as $\mathrm{Q}=($ concentration in $\mathrm{CSF}[\mathrm{mg} / \mathrm{L}] /$ concentration in serum $[\mathrm{g} / \mathrm{L}])$. Because QAlb increases with age, we calculated a maximum normal QAlb (QNorm) for each patient that takes into account the age at lumbar puncture $(\mathrm{QNorm}=$ [age/15] $\left.+4 \times 10^{-3}\right) \cdot{ }^{10}$ Intrathecal Ig synthesis $(\operatorname{Ig}(\operatorname{loc}))$ was calculated using hyperbolic functions according to Reiber and expressed as percentage (\%). ${ }^{11}$ Identification of CSFrestricted oligoclonal bands was performed by isoelectric focusing.

\section{HLA Typing}

Patients were typed for human leukocyte antigen (HLA) class I $\left(\mathrm{A}^{*}\right.$ and $\left.\mathrm{B}^{*}\right)$ and II (DRB1*, DRB3 ${ }^{*}, \mathrm{DRB}^{*}, \mathrm{DRB5}^{*}$, DQA1 ${ }^{*}$ and $\left.\mathrm{DQB1} 1^{*}\right)$ molecules using high-resolution HLA sequence-based typing at Histogenetics LLC, Ossining, NY. Isolation of DNA from whole blood with a final concentration of $15 \mathrm{ng} / \mu \mathrm{L}$ was performed with a standard DNA isolation 
Figure 2 Characterization of CSF-Infiltrating Cells and Markers of CNS Damage in Patients With MS With and Without Increased QAlb

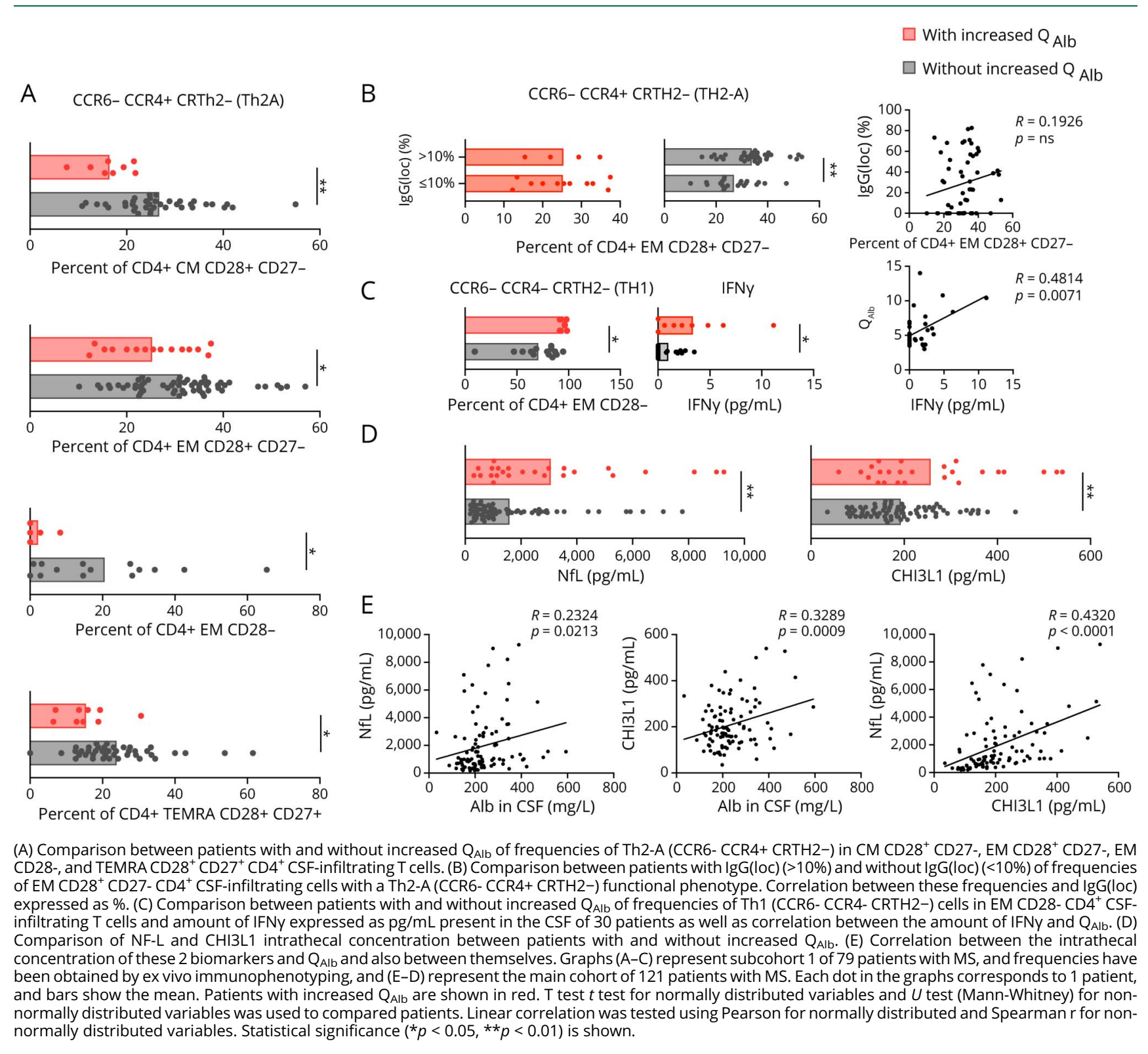

protocol using a Triton lysis buffer and proteinase $\mathrm{K}$ treatment.

\section{Flow Cytometric Immunophenotyping}

Flow cytometric immunophenotyping of CSF-infiltrating and paired circulating lymphocytes was performed as previously reported. ${ }^{12}$ Briefly, a minimum of 10,000 CSF-infiltrating cells were concentrated by centrifugation and processed in the first hour after collection. Blood circulating cells were obtained from $800 \mu \mathrm{L}$ of peripheral blood after lysis of red blood cells (RBCs) using RBC Lysis buffer (BioLegend, San Diego, CA). Cells were stained with a cocktail of 13 monoclonal antibodies. ${ }^{12}$

SPHERO AccuCount Particles (Sperotech, Inc., Lake Forest, IL) were added to determine absolute counts following manufacturer's instructions. Sample acquisition was performed in an LSR Fortessa cytometer (BD Biosciences, Franklin Lakes, NJ), and data were analyzed using FACSDiva (BD) and FlowJO (TreeStar Inc., Ashland, OR) software. The gating strategy is summarized in figure e-1 (links.lww. com/NXI/A413).

\section{Legend Plex and ELISAs}

Cytokines directly in the CSF were measured using the $\mathrm{Hu}-$ man T Helper Cytokine Panel LEGENDplex bead-based immunoassay (BioLegend) according to the manufacturer's instructions.

Intrathecal neurofilament light chain (NF-L) and chitinase 3-like 1 (CHI3L1) proteins were quantified in CSF samples 
Figure 3 Lipidomic Profile in Patients With MS With and Without Increased Alb $_{\text {Alb }}$
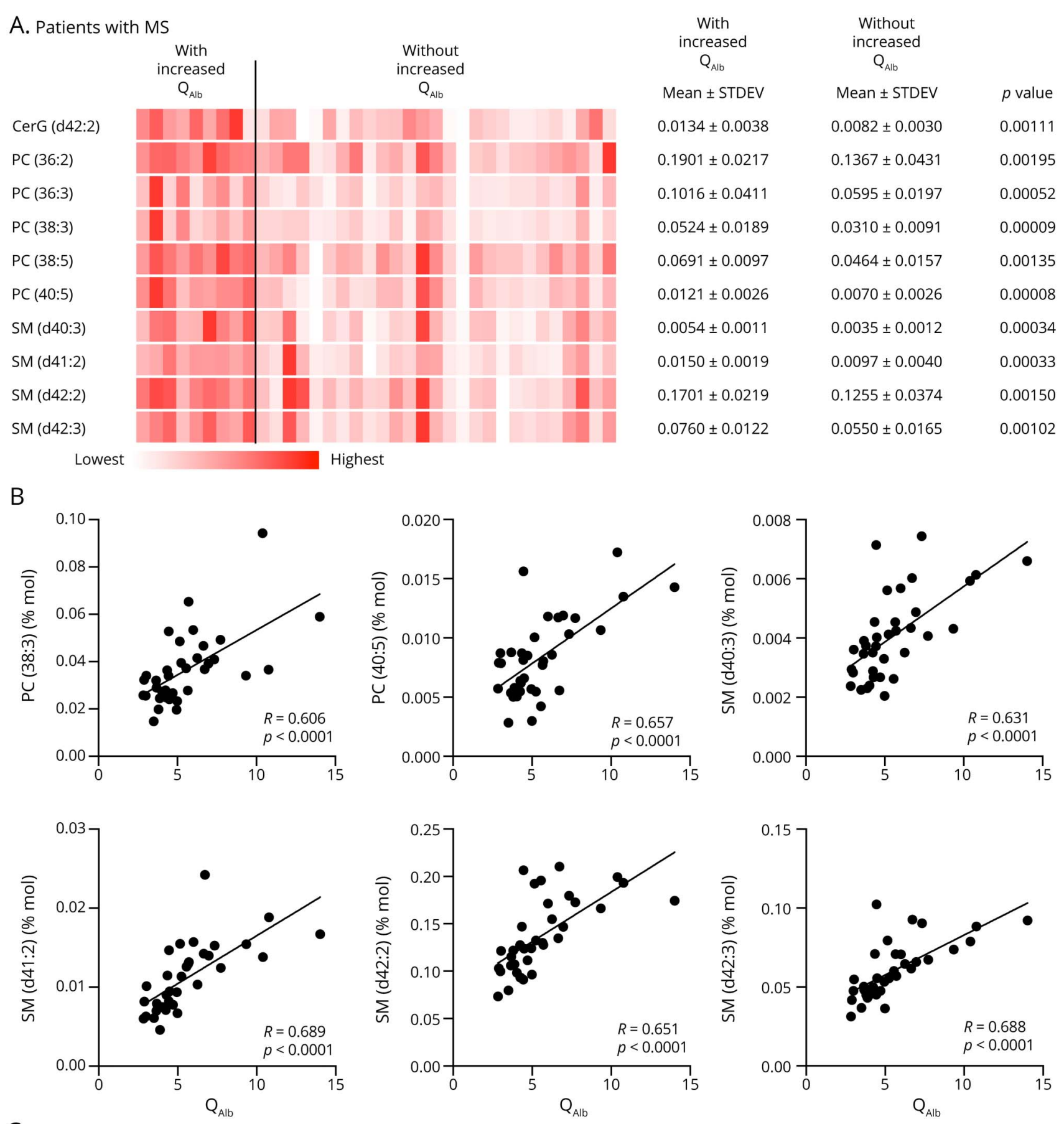

C

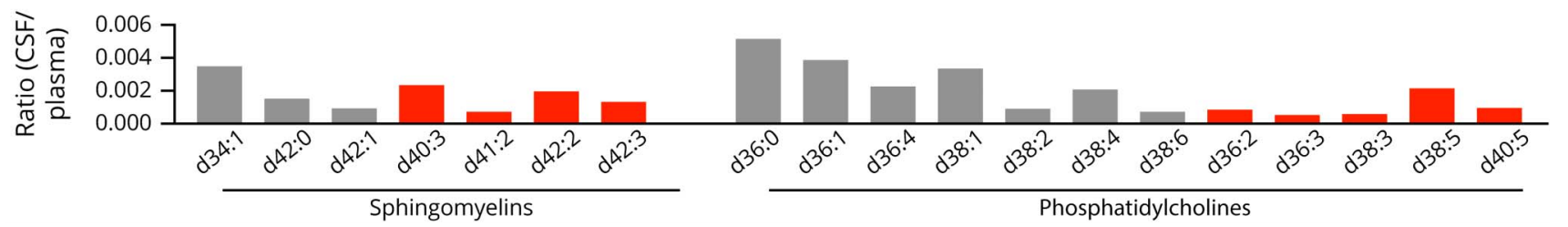

(A) Heat map of the 10 statistically most significant altered lipid species between patients with MS with and without increased $\mathrm{Q}_{\mathrm{Alb}}$. The abundance of the lipid species is qualitatively represented by color intensity for each of the 36 patients with MS (subcohort 2). Mean, SD, and $p$ values of the group comparisons are shown. (B) Correlations between $Q_{A l b}$ and the intrathecal concentration for 6 of the identified lipid species. Linear correlation between variables was tested using Pearson correlation, and $p$ values are shown. (C) Ratios between mean CSF concentration of lipid species in patients with MS and the concentration in plasma from a reference control cohort with 24 healthy controls. Marked in red are the 4 SM and 5 PC species that were significantly more abundant in patients with MS with increased $Q_{\text {Alb. }}$ Ig = immunoglobulin; QAlb = serum albumin quotient. 

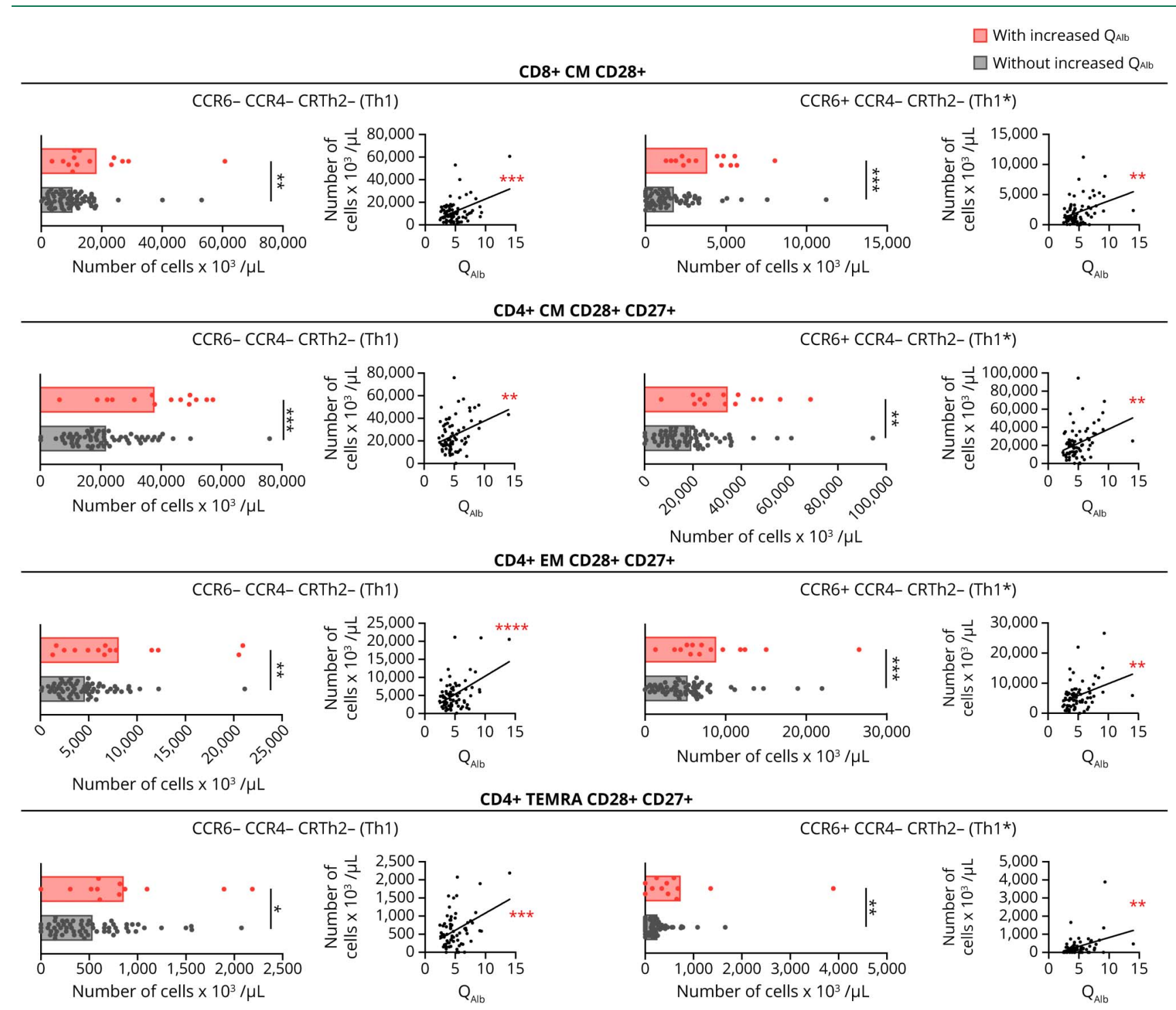

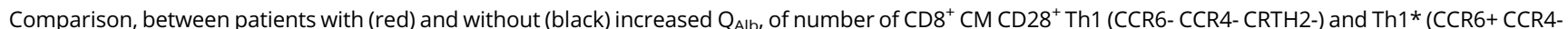
CRTH2-), CD4 ${ }^{+}$CM CD28 ${ }^{+}$CD27 ${ }^{+}$Th1 (CCR6- CCR4- CRTH2-) and Th1* (CCR6+ CCR4- CRTH2-), CD4 ${ }^{+}$EM CD28 ${ }^{+}$CD27 ${ }^{+}$Th1 (CCR6- CCR4- CRTH2-) and Th1*

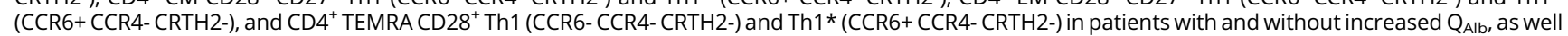
as the correlation between these cell counts and $Q_{\text {Alb. }}$. All graphs represent subcohort 1 consisting of 79 patients with MS. Each dot in the graph corresponds to a single patient, and bars show the mean. T test $t$ test for normally distributed variables and U test (Mann-Whitney) for non-normally distributed variables was used to compared patients. Linear correlation was tested using Pearson for normally distributed and Spearman $r$ for non-normally distributed variables. Statistical significance $\left({ }^{*} p<0.05,{ }^{* *} p<0.01,{ }^{* *} p<0.001\right.$, and $\left.{ }^{* * * *} p<0.0001\right)$ is shown. Statistical significance $\left({ }^{*} p<0.05,{ }^{* *} p<0.01,{ }^{* *} p<0.001\right.$, and ${ }^{* * * *} p<$ $0.0001)$ is shown. QAlb = serum albumin quotient.

by ELISA (Human Diagnostics, Umea, Sweden, and MicroVue, Athens, $\mathrm{OH}$, respectively) according to the manufacturer's instructions.

\section{Lipid Extraction and Lipidomics}

Lipid extraction was performed as previously described ${ }^{13}$ with some modifications. The MMC solvent (methanol: methyl tert-butyl ether: chloroform, 4:3:3, vol:vol:vol) was supplemented with the SPLASH mix internal standard and additional internal standards (all from Avanti Polar Lipids): d7-sphinganine ( $\mathrm{SPH}$ d18:0), d7-sphingosine ( $\mathrm{SPH}$ d18:1), dihydroceramide (Cer d18:0/12:0), ceramide
(Cer d18:1/12:0), glucosylceramide (GluCer d18:1/8:0), sphingomyelin (SM d18:1/12:0), and d7-sphingosine-1phosphate (S1P d18:1). Liquid chromatography was performed according to Ref. 14 with some modifications. Lipids were separated using a C30 Accucore LC column $(150 \times 2.1 \mathrm{~mm}, 2.6 \mu \mathrm{m}$ particle size $)$ and a Transcend UHPLC pump (Thermo Fisher Scientific). Mass spectrometry analysis was performed on a hybrid quadrupoleorbitrap mass spectrometer (Q-Exactive; Thermo Fisher Scientific). Lipid identification criteria were (1) resolution with an accuracy of $5 \mathrm{ppm}$ from the predicted mass at a resolving power of 70,000 at $200 \mathrm{~m} / \mathrm{z}$, (2) isotopic 

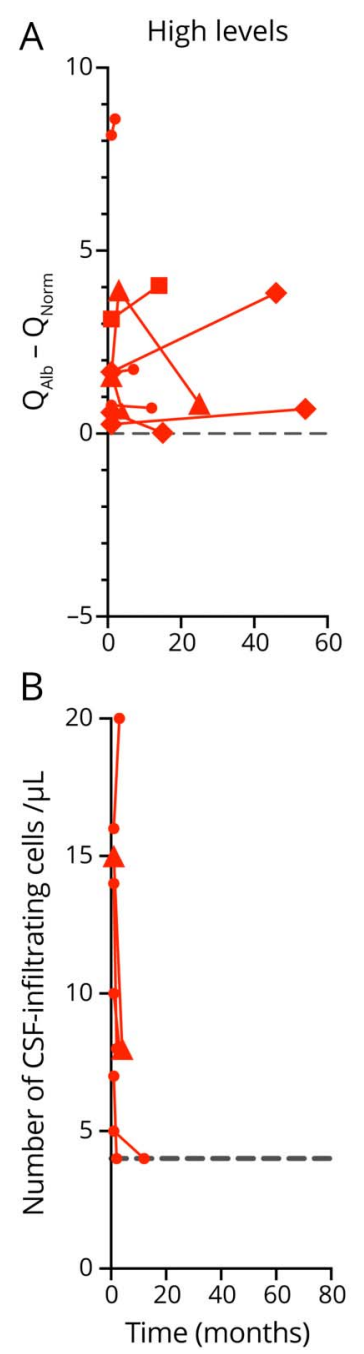

Low levels
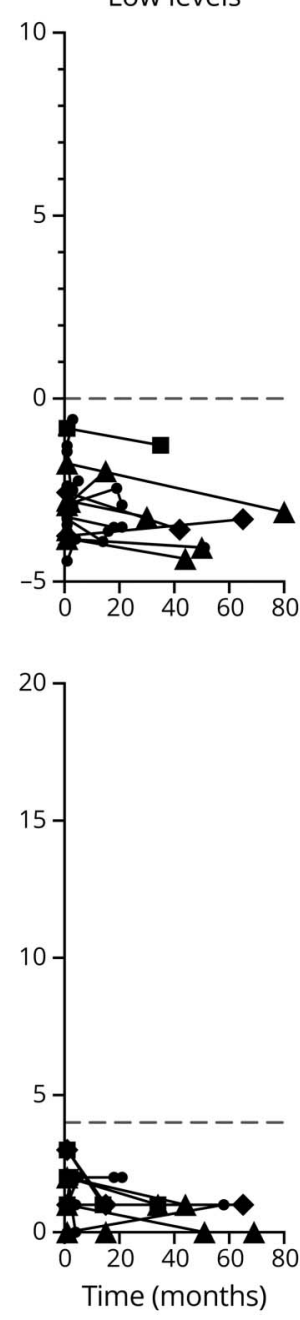

Change
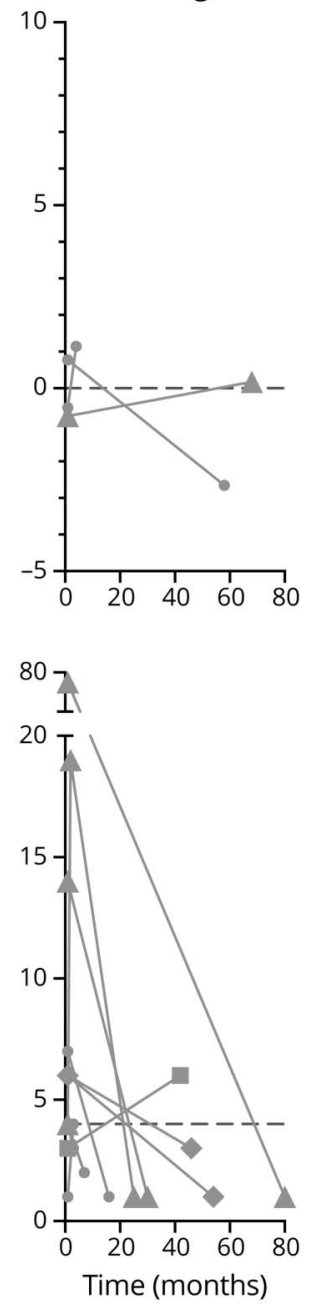

( $A$ and $B$ ) Linear representations of $Q_{A l b}$ minus $Q_{N o r m}$ values (B) and number of CSF-infiltrating cells per $\mu \mathrm{L}$ (C) over time in a cohort of 33 patients with MS from which CSF samples at different time points were available. $X$-axis represents time in months, and $\mathrm{Y}$-axis represents $\mathrm{Q}_{\text {Alb }}$ - $\mathrm{Q}_{\text {Norm }}$ and number of CSF-infiltrating cells per $\mu \mathrm{L}$. The number of patients in each graph is indicated. The dotted line represents the limit for normal values ( 0 for QAlb-QNorm and 4 for number of CSFinfiltrating cells). Patients who maintain high levels over time are shown in red, those who maintain low levels in black, and those who change the levels in gray. Fine lines and circles correspond to untreated patients. Patients treated between lumbar punctures are shown with bold lines and squares (dimethyl fumarate), triangles (natalizumab), and diamonds (fingolimod). QAlb = serum albumin quotient; QNorm = normal QAlb. distribution, (3) expected retention time, and (4) fragmentation pattern.

Data analysis was performed using TraceFinder 4.1 (Thermo Fisher Scientific) for peak picking, annotation, and matching to an in-house lipid database.

\section{Statistics}

For comparison of 2 groups of patients, we used the unpaired $t$ test for normally distributed variables and the $U$ test (Mann-Whitney) for non-normally distributed variables. Linear correlation between variables was tested using Pearson for normally distributed and Spearman $\mathrm{r}$ for nonnormally distributed variables. The significance level was set at $p<0.05$.

\section{Data Availability}

Any data not published within the article because of space limitations will be shared as anonymized data by request from any qualified investigator for purposes of replicating procedures and results.

\section{Results}

\section{Patients With MS With Increased QAlb}

We determined the QAlb in our cohort of 121 patients with MS, and, assuming that this parameter increases with age, we marked a maximum QNorm for each patient as explained in $M \& M$. We defined patients with increased QAlb as patients having a QAlb > QNorm. We used increased QAlb as indicator of $\mathrm{BBB}$ permeability although we are aware that it is not a perfect measurement because other factors such as altered CSF flow due to meningeal inflammation might influence it. ${ }^{15}$ Based on this definition of increased QAlb, 30 (24.8\%) of patients with MS had an increased QAlb and 91 (75.2\%) not (figure 1A). Demographic and clinical features of these patients are summarized in table 1 . None of these parameters showed significant differences between patients with 

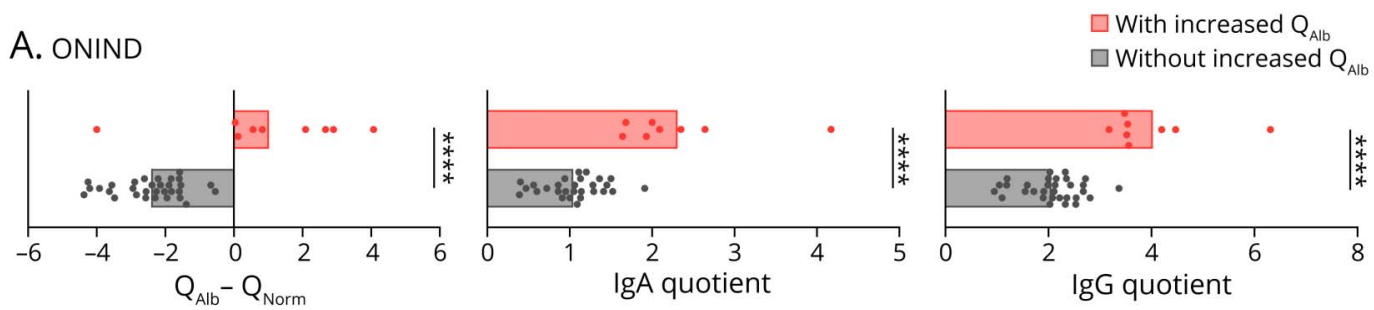

CSF-infiltrating cells
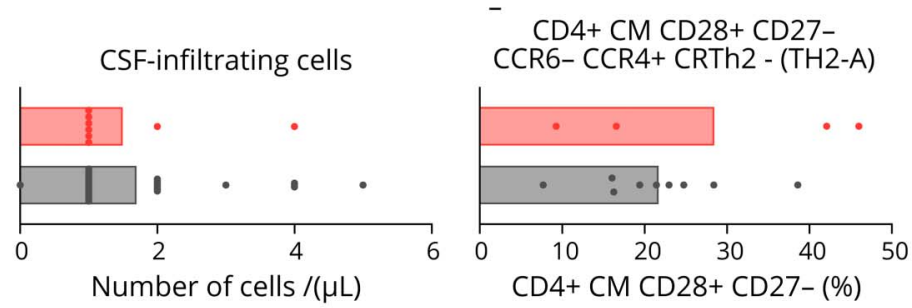

CD4+ EM CD28+ CD27 CCR6- CCR4+ CRTh2- (TH2-A)

B. OIND
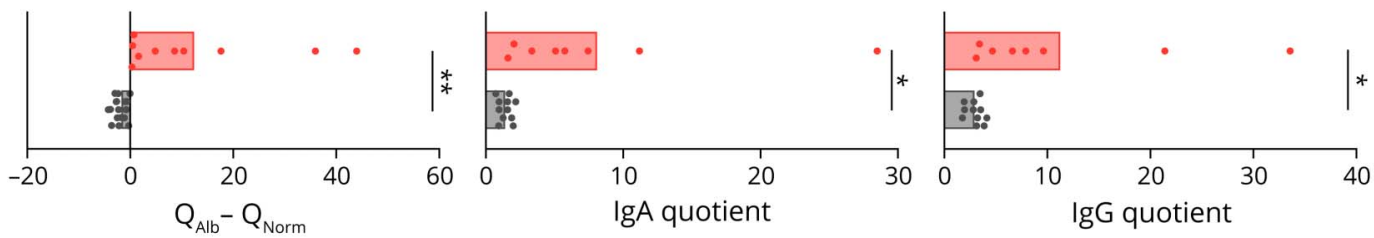

CSF-infiltrating cells

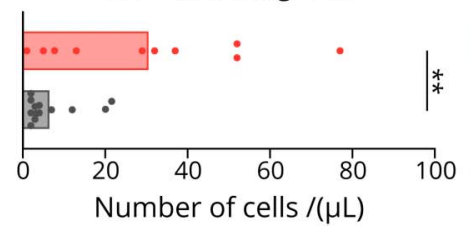

$\mathrm{CD} 4+\mathrm{CM} \mathrm{CD} 28+\mathrm{CD} 27-$ CCR6- CCR4+ CRTh2- (TH2-A)
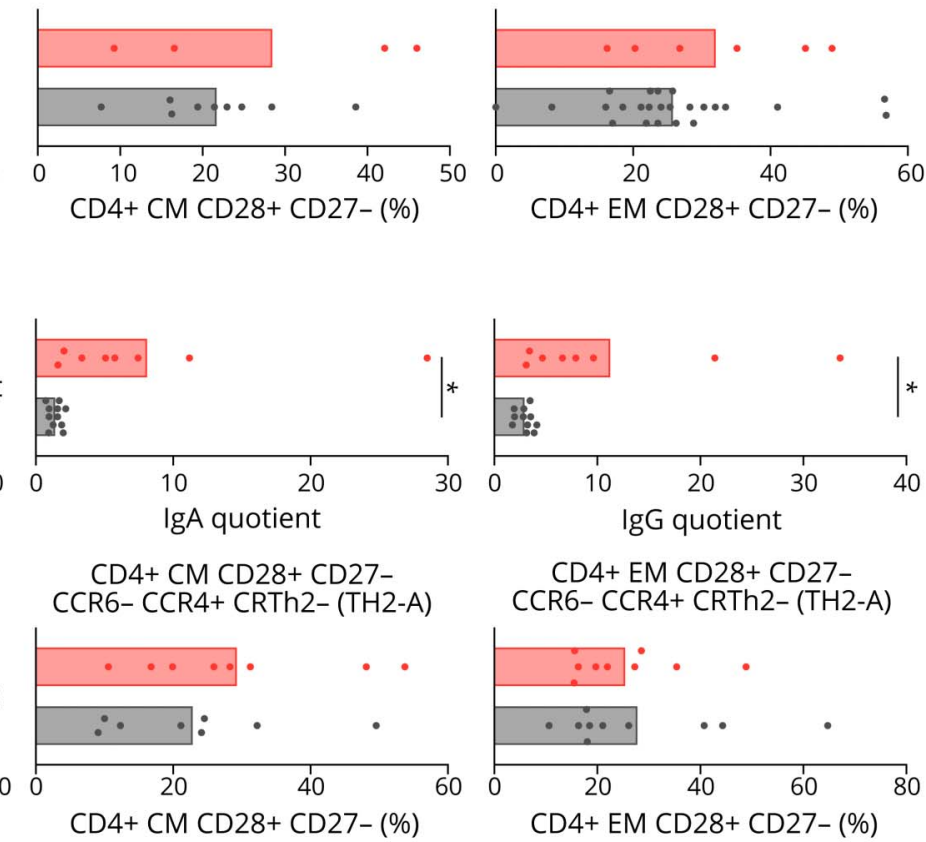

CD4+ EM CD28+ CD27CCR6- CCR4+ CRTh2- (TH2-A)

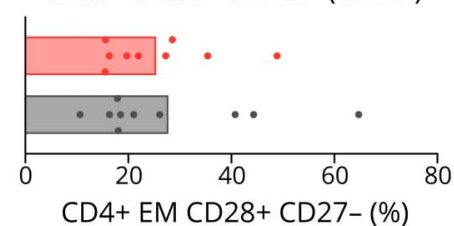

(A and B) QAlb minus QNorm has been used like in patients with MS to differentiate controls with (in red) and without (in black) increased QAlb. Comparison between controls (ONIND [ $n=40](A)$ and OIND $[n=21](B)$ ) with and without increased QAlb of IgA and IgG quotient, CSF-infiltrating cells, and frequency of TH2-A (CCR6- CCR4+ CRTH2-) and TH2-B (CCR6- CCR4+ CRTH2+) in CD4 ${ }^{+}$CM CD28 ${ }^{+}$CD27- and in CD4 ${ }^{+}$EM CD28 ${ }^{+}$CD27- CSF-infiltrating cells. In all graphs, each dot corresponds to 1 patient, and bars show the mean. T test $t$ test for normally distributed variables and $U$ test (Mann-Whitney) for non-normally distributed

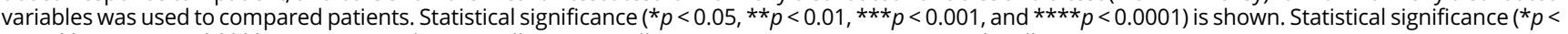
$0.05, * \star p<0.01$, and $* \star \star \star x p<0.0001$ ) is shown. QAlb = serum albumin quotient; QNorm = normal QAlb.

MS with and without increased QAlb. HLA typing of these patients demonstrated that the expression of the MSassociated DR15 haplotype was also comparable in both groups of patients (table 1). We did not find any HLA class I or class II molecule over- or under-represented in patients with increased QAlb (data not shown).

\section{CSF Measures in Patients With MS With Increased QAlb}

IgA quotients were much higher in patients with MS with increased QAlb, IgG quotients were also significantly higher in these patients although to a lesser extent, and minimal differences were found for IgM quotients (figure 1B). In contrast, the indices for these 3 Igs corrected for albumin concentration (see M\&M) were comparable in both groups of patients suggesting a strong association between the traffic of albumin and IgA and to a lesser extent IgG (table 1). Regarding the Igs(loc), only IgG(loc) was significantly lower in patients with increased QAlb (table 1 and figure 1B). Total CSF protein was significantly higher in patients with MS with increased QAlb, whereas serum albumin, intrathecal lactate, and glucose quotient were comparable in patients with and without increased QAlb (table 1).

\section{CSF-Infiltrating Cells in Patients With MS With Increased QAlb}

CSF analysis under the microscope showed comparable numbers of CSF-infiltrating cells in patients with and without increased QAlb, but different composition. CSF from patients with increased QAlb contains less lymphocytes but significantly more monocytes (figure 1C). This different cell composition of the CSF might underlie the lower correlation between $\operatorname{IgG}(\mathrm{loc})$ and number of CSF-infiltrating cells in patients with increased QAlb (figure 1D). Flow cytometry immunophenotyping of CSF and paired blood from a subcohort of 79 patients with MS (table 1 , subcohort 1$)^{12}$ allowed a detailed characterization of 
A. ONIND

CD8+ CM CD28+

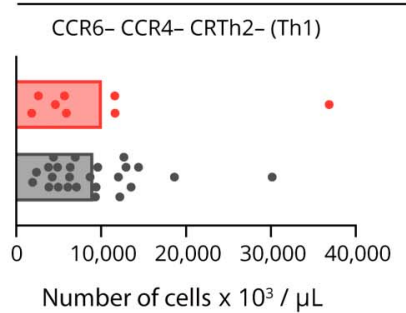

CD4+ EM CD28+CD27+

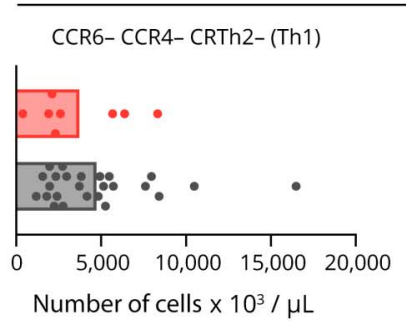

CCR6+ CCR4- CRTh2- (Th1*)

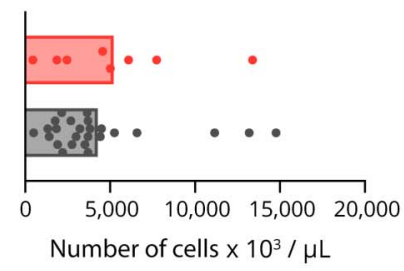

B. OIND

CD8+ CM CD28+

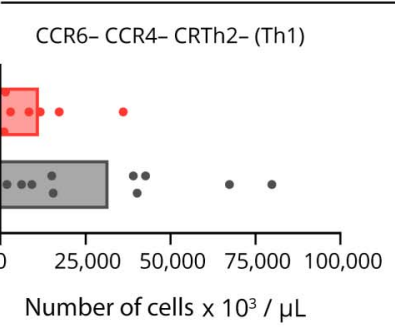

CCR6+ CCR4- CRTh2- (Th1*)

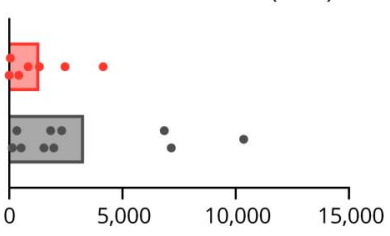

Number of cells $\times 10^{3} / \mu \mathrm{L}$

CD4+ EM CD28+ CD27+

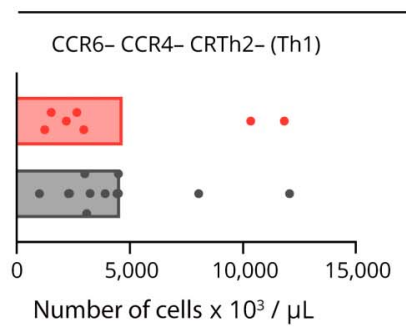

CCR6+ CCR4- CRTh2- (Th1*)

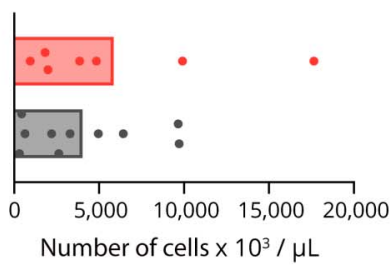

CD4+ CM CD28+ CD27+

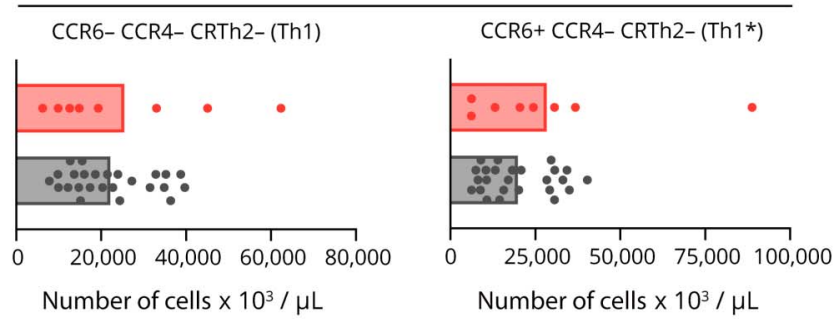

CD4+ TEMRA CD28+ CD27+

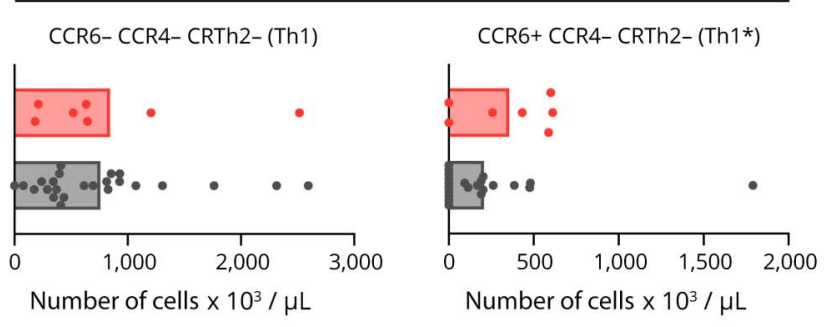

CD4+ CM CD28+ CD27+

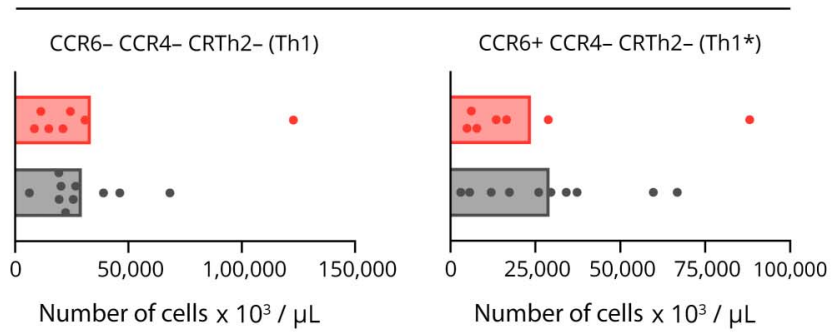

CD4+ TEMRA CD28+ CD27+

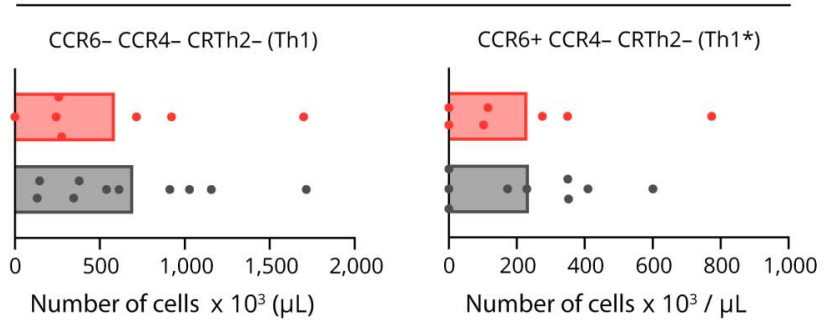

(A and B) Comparison between controls (ONIND $[n=40](A)$ and OIND $(n=21)(B)$ ) with and without increased QAlb of number of: CD8 ${ }^{+} C M$ CD28 $8^{+}$Th1 (CCR6- CCR4- CRTH2-) and Th1* (CCR6+ CCR4- CRTH2-), CD4 ${ }^{+}$CM CD28 ${ }^{+}$CD27 ${ }^{+}$Th1 (CCR6- CCR4- CRTH2-) and Th1 (CCR6+ CCR4- CRTH2-), CD4 ${ }^{+}$EM CD28 ${ }^{+}$ CD27 ${ }^{+}$Th1 (CCR6- CCR4- CRTH2-) and Th1* (CCR6+ CCR4- CRTH2-), and CD4+ TEMRA CD28+ Th1 (CCR6- CCR4- CRTH2-) and Th1* (CCR6+ CCR4- CRTH2-) circulating cells. Cell counts have been determined using SPHEROTM AccuCount Particles. In all graphs, each dot corresponds to 1 patient, and bars show the mean. T test $t$ test for normally distributed variables and $\mathrm{U}$ test (Mann-Whitney) for non-normally distributed variables was used to compared patients.

CSF-infiltrating and circulating lymphocytes (table e-1, links. lww.com/NXI/A413). Although most of the CSF-infiltrating cells in patients with and without increased QAlb showed similar frequencies, we found that $\mathrm{CD} 4^{+} \mathrm{T}$ cells with a Th2-A functional phenotype, based on the combination of chemokine receptors $\left(\mathrm{CCR} 6^{-} \mathrm{CCR}^{+}{ }^{+} \mathrm{CRTh} 2^{-}\right)$, and the following different maturation states: (1) $\mathrm{CM}$ and $\mathrm{EM} \mathrm{CD} 28^{+} \mathrm{CD} 27^{-}$ $\mathrm{CD}^{+} \mathrm{T}$ cells, that have downregulated $\mathrm{CD} 27$ most likely following repetitive stimulation with antigen, ${ }^{16}$ (2) EM CD28 $8^{-}$and (3) TEMRA CD $28^{+} \mathrm{CD} 27^{+}$, were all significantly reduced in patients with increased QAlb (table e-1, figure e-2A, and figure 2A). Patients with MS with increased QAlb showed lower levels of these $\mathrm{Th} 2 \mathrm{CD} 4{ }^{+} \mathrm{T}$ cells than patients without increased QAlb independently of disease activity and most likely clinical form of the disease (data not shown). Th2 cells are required for humoral immunity, and accordingly, we found 
a significant association between the frequencies of $\mathrm{EM} \mathrm{CD} 28^{+}$ $\mathrm{CD} 27^{-} \mathrm{CD}^{+}$Th2-A cells and IgG(loc) (\%) (figure 2B). Patients with increased QAlb also showed significantly higher frequencies of EM CD28- $\mathrm{TH} 1$ cells as well as significantly higher amounts of IFN $\gamma$ in the CSF that correlated with QAlb (figure 2C). None of the other 12 cytokines showed differences between patients with and without increased QAlb (figure e-2B). The frequencies of these cell types in peripheral blood were comparable between patients with and without increased QAlb (table e-1 and figure e-2C).

\section{Markers of CNS Damage in Patients With MS With Increased QAlb}

Because previous studies associated increased QAlb with higher disability in patients with $\mathrm{MS},{ }^{7,8}$ we explored indicators of CNS damage in our cohort of 121 patients with MS using 2 promising biomarkers: NF-L, a cytoskeletal component of neurons that is very abundant in axons, ${ }^{17}$ and it has been associated with BBB integrity, ${ }^{18}$ and $\mathrm{CHI} 3 \mathrm{~L} 1$, a glycoprotein secreted by activated glia. ${ }^{19}$ Our results demonstrated that the intrathecal quantity of both biomarkers was statistically higher in the CSF of patients with increased QAlb (figure 2D), and their amount correlated with QAlb and with each other as already reported ${ }^{20}$ (figure $2 \mathrm{E}$ ). The higher amount of NF-L and CHI3L1 in patients with MS with increased QAlb does not seem to be related to disease activity or clinical form of the disease (data not shown), although the low number of patients with radiologically isolated syndrome/clinically isolated syndrome and progressive MS forms limits conclusions.

Next, we used liquid chromatography/mass spectrometry to analyze the lipidomic profile in a subcohort of 36 patients with MS (table 1, subcohort 2). Because the brain has the second highest lipid content after adipose tissue, lipids are the main components of myelin sheaths and changes in lipid metabolism have been observed in damaged cells, we used lipidomics to explore CNS damage. The total lipid content in CSF reflected about $0.1 \%-0.5 \%$ of the plasma levels. In total, we identified 510 different lipid species in CSF of which 105 passed the QC criteria $\left(R^{2}>0.9+\mathrm{CV}\right.$ $<20 \%)$. The intrathecal concentrations of 10 species were significantly higher in the CSF of patients with increased QAlb (figure $3 A$ ). The majority of these species showed a significant correlation with QAlb, whereas the strongest association was seen for the phosphatidylcholines (PCs) PC (38:3) and PC (40:5) and the sphingomyelins (SMs) SM (d40:3), SM (d41:2), SM (d42:2), and SM (d42:3) (figure 3B). Comparing the lipid profile in the CSF from patients with MS with the plasma levels from an independent reference cohort $(\mathrm{n}=32)$ showed a distinct CSF/ plasma ratio for the individual species indicating that this increased in the intrathecal lipids was selective and not simply caused by diffusion from plasma (figure 3C).

\section{Peripheral Inflammation in Patients With MS With Increased QAlb}

Because previous studies associated increased QAlb with systemic inflammation in patients with abnormal CSF measures, ${ }^{6}$ we quantified peripheral blood lymphocytes in MS subcohort 1 (table 1) using flow cytometry immunophenotyping and counting beads. Although the frequencies of the lymphocyte subtypes did not show significant differences between patients with and without increased QAlb, the real counts of several of these cells did (table e-1, links.lww.com/NXI/A413). Patients with increased QAlb had significantly higher counts of circulating $\mathrm{CD}^{+} \mathrm{T}$ cells, $\mathrm{CD}^{+}$, and in particular $\mathrm{CD} 4^{+}$cells (table e-1). For each T-cell type, particularly CM and EM cells were increased (table e-1). Regarding the functional phenotype of these $\mathrm{T}$ cells, $\mathrm{CM} \mathrm{CD} 28^{+} \mathrm{CD} 8^{+} \mathrm{T}$ cells and $\mathrm{CM}, \mathrm{EM}$, as well as TEMRA CD $28^{+} \mathrm{CD} 27^{+} \mathrm{CD} 4^{+} \mathrm{T}$ cells, all with Th1 (CCR6 ${ }^{-}$ $\left.\mathrm{CCR}^{-} \mathrm{CRTh}^{-}\right)$and $\mathrm{Th}^{*}\left(\mathrm{CCR}^{+}{ }^{+} \mathrm{CCR}^{-}{ }^{-} \mathrm{CRTh} 2^{-}\right)$ functional phenotypes were significantly increased in the blood of patients with increased QAlb (figure 4). In addition, a statistically significant correlation between the number of these T-cell subtypes in blood and the QAlb was observed (figure 4).

Disease activity and the clinical form of the disease does not seem to influence the higher frequency of these cells in patients with MS with increased QAlb (data not shown).

\section{Increased Albumin Quotient Is Preserved Over Time}

CSFs from 33 patients with MS were analyzed at different time points. All patients were untreated at the first time point. Eleven patients (33.3\%) had increased QAlb at the first time point and 10 of these patients (83.3\%) maintained increased QAlb over time, in 2 patients for even more than 40 months (figure 5A). Six of these patients received treatment between lumbar punctures ( 1 dimethyl fumarate, 3 fingolimod, and 2 natalizumab), whereas 4 patients remained untreated. The increased QAlb disappeared only in 1 patient after 58 months without treatment. Of the 22 patients without increased QAlb at the first time point, only 2 showed increased QAlb in subsequent analyses (figure 5A). Although some treatments can have an effect on BBB permeability and reduced QAlb values, our results suggest that in patients with increased QAlb the reduction to normal QAlb values is not easy and, if possible, it might take time.

We analyzed the number of CSF-infiltrating cells in the same samples. Fifteen patients (45.45\%) had more than 4 CSFinfiltrating cells per $\mu \mathrm{L}$ at the first time point, but only 6 of these patients (40\%) maintained elevated CSF cell counts over time and no patient for more than 20 months (figure 5B).

Regarding the 16 patients with low CSF cell counts at the first time point, only 2 patients showed increased numbers over time (figure 5B).

\section{Increased QAlb in ONIND and OIND}

Finally, we examined whether the differences in CSF-infiltrating and circulating lymphocytes between patients with MS with and without increased QAlb were also present in controls (table 1). Using the definition of increased QAlb as QAlb > QNorm, we identified 9 (22.5\%) ONIND and 10 (47.6\%) OIND patients with increased QAlb and 31 (77.5\%) ONIND and 11 (52.4\%) 
OIND patients without (figure 6, A and B). As observed in patients with MS, all controls with increased QAlb showed significantly higher intrathecal IgA and IgG (figure 6, A and B). The number of CSF-infiltrating cells was comparable between ONIND controls with and without increased QAlb, whereas it was significantly higher in OIND controls with increased QAlb (figure 6, A and B). The differences in CSF-infiltrating and peripheral blood lymphocytes that we observed in patients with MS with and without increased QAlb were not found in controls (figure 7, A and B).

\section{Discussion}

Different studies ${ }^{2-6}$ have suggested that CNS damage may increase the susceptibility of the BBB to changes induced by systemic inflammation such as increased vesicular trafficking of albumin. MS is a complex immune-mediated disease that affects the CNS and BBB permeability. ${ }^{21}$ In some patients with MS, CNS damage and systemic inflammation may coexist and influence BBB function. With the aim to better understand BBB permeability in MS and to investigate a putative role of CNS damage and systemic inflammation on $\mathrm{BBB}$ dysfunction, we identified patients with MS with increased QAlb and characterized them in detail. The comparison of demographic and clinical features between patients with MS with and without increased QAlb did not reveal any statistically significant difference, although the limited clinical data did not allow a definitive statement. Unfortunately, neither longitudinal MRI data nor longitudinal disability measures were available from our cohort to confirm the previously reported association between increased QAlb and greater deterioration in patients with MS.,

However, the detailed analysis of CSF revealed interesting differences between patients with and without increased QAlb. Patients with MS with increased QAlb showed significantly higher intrathecal levels of IgA and IgG and to a lesser extent of IgM. Because the indices of IgA and IgG, in which the values are corrected for the traffic of albumin, were comparable between patients, our results suggest that the passage of $\operatorname{IgA}$ and $\operatorname{IgG}$ across the BBB is most likely associated with the passage of albumin. IgM with its pentameric nature, much larger size, and molecular weight may not use vesicular trafficking. Patients with MS with increased QAlb also showed reduced $\mathrm{IgG}(\mathrm{loc})$. Regarding the CSF infiltrate, although the number of infiltrating cells was comparable in patients with and without increased QAlb, the cellular composition was different. Patients with MS with increased QAlb contained significantly more monocytes.

Because monocytes are not involved in antibody production, the correlation between CSF-infiltrating cells and $\operatorname{IgG}(\operatorname{loc})$ was significantly lower in patients with increased QAlb. Of interest, mediators involved in BBB dysfunction such as reactive oxygens species ${ }^{22}$ and matrix metalloproteinase $9^{23}$ are produced by monocytes. Our ex vivo immunophenotyping of CSF- infiltrating lymphocytes demonstrated that patients with MS with increased QAlb and reduced $\operatorname{IgG}(\mathrm{loc})$ also showed significantly lower frequencies of $\mathrm{CD} 4^{+} \mathrm{T}$ cells with a Th2 functional phenotype. In particular, the following $\mathrm{CD} 4+\mathrm{T}$ cell subsets: $\mathrm{CM}$ and $\mathrm{EM} \mathrm{CD} 28^{+} \mathrm{CD} 27^{-} \mathrm{CD} 4^{+} \mathrm{T}$ cells, which may be relevant due to their downregulation of $\mathrm{CD} 27$ after repetitive stimulation with antigen, ${ }^{16} \mathrm{EM} \mathrm{CD} 28^{-}$and TEMRA $\mathrm{CD} 28^{+} \mathrm{CD} 27^{+} \mathrm{CD} 4^{+} \mathrm{T}$ cells. Th2 cells are relevant for humoral immunity, and accordingly, we demonstrated an association between these cells and intrathecal IgG synthesis. Th2 cells, in addition to their role in humoral immunity, may also have a protective anti-inflammatory role as has been assumed in some MS clinical trials aimed to deviate immune responses from Th1 toward Th2. ${ }^{24}$ Their reduction in patients with MS with increased QAlb might thus have harmful consequences. We also found that EM CD28- $\mathrm{CD}^{+} \mathrm{T}$ cells with a Th1 functional phenotype were significantly higher in patients with increased QAlb as well as the amount of IFN $\gamma$ in the CSF. Long-term memory $\mathrm{CD} 4^{+} \mathrm{CD} 28^{-} \mathrm{T}$ cells can produce high amounts of IFN $\gamma$ in the absence of costimulation and showed increased survival and proliferation capacity after activation. ${ }^{25}$ Their putative role in MS is supported by their expansion in a subgroup of patients with MS and their myelin basic protein specificity. ${ }^{26}$ Immunophenotyping of paired blood samples did not show the same differences that have been observed between patients by CSF analyses. It is therefore unlikely that mere bystander traffic is responsible for the changes in the CSF. The higher concentration of IgG and IgA observed in patients with MS with increased QAlb, as well as the higher frequency of monocytes, the higher amount of IFNg and the lower frequency of potentially protective $\mathrm{Th} 2 \mathrm{CD} 4+\mathrm{T}$ cells might facilitate CNS damage in these patients. Accordingly, our results demonstrate that patients with MS with increased QAlb show significantly higher levels of biomarkers of CNS damage and inflammation such as NF-L and CHI3L1 and support previous studies, in which increased QAlb in patients with MS was found to be associated with atrophy and greater deterioration ${ }^{7,8}$ as well as higher levels of serum NF-L. ${ }^{18}$ In addition, we identified 10 intrathecal lipid species that are more abundant in patients with MS with increased QAlb.

Although we do not know the underlying mechanisms, the increase of these lipids may be involved in CNS damage. Two of the 4 identified SM species contained a Sphingadienine (SAdienine) long chain base, which is formed as a downstream product of sphingosine via fatty acid desaturase 3 (FADS3). ${ }^{27}$ The increase in SAdienine-based SM suggests a possible role of FADS 3 in this process. Of interest, a previous study linked changes in the same SAdienine-based SM species to an increased activity of acid sphingomyelinase, which converts SM to ceramide. ${ }^{28}$ The activation of the acid sphingomyelinase/ceramide system has been demonstrated to be a central step for the development of EAE. ${ }^{29}$

Regarding a putative association between systemic inflammation and BBB permeability in patients with MS, our results demonstrate that several lymphocyte populations, in 
particular T cells with a Th1 and Th1* functional phenotype, were significantly more abundant in patients with MS with increased QAlb and cell counts correlated with QAlb. Of interest, this association was not observed in controls patients with ONIND and OIND diseases, suggesting that the type of systemic inflammation that might influence $\mathrm{BBB}$ permeability most likely differs between pathologies. Unfortunately, the usual and easy-to-determine markers of systemic inflammation such as C-reactive protein or neutrophil counts were not available from the blood taken at the time of lumbar puncture.

The coexistence of markers of CNS damage and systemic inflammation in patients with MS with increased QAlb supports a putative role of CNS damage in increasing BBB vulnerability to systemic inflammation in these patients. Because the capacity of remyelination is limited and neuroregenerative treatments are missing, we can assume that CNS damage might persist over time. Accordingly, increased QAlb in patients with MS was also preserved over time even after initiating immunomodulatory treatments. It will be interesting to see in the future if treatments or treatment combinations with neuroregenerative potential have an effect on QAlb. Finally, given that CNS damage and systemic inflammation vary among patients with MS and influence BBB permeability, also it will be of interest to examine their impact on MS heterogeneity and its value in patient classification. Patients with increased QAlb might especially profit from a better control of systemic inflammation as well as from neuroprotective/ neuroregenerating treatment approaches.

\section{Study Funding}

European Research Council Advanced Grant (340733) (R.M.), Clinical Research Priority Program MS (CRPPMS) and (CRPP) PrecisionMS of the University Zurich (R.M., M.S., and A.L.), Clinical, Swiss National Science Foundation (Sinergia UnmetMS) (R.M. and M.S.), and the Swiss MS Society (R.M.).

\section{Disclosure}

The authors declare that they have no competing financial interests in the context of this work. Go to Neurology.org/ $\mathrm{NN}$ for full disclosures.

\section{Publication History}

Received by Neurology: Neuroimmunology \& Neuroinflammation June 3, 2020. Accepted in final form October 6, 2020.

Appendix Authors

\begin{tabular}{lll}
\hline Name & Location & Contribution \\
\hline $\begin{array}{l}\text { Marco } \\
\text { Puthenparampil, } \\
\text { MD, PhD }\end{array}$ & $\begin{array}{l}\text { University Hospital and } \\
\text { University Zurich, } \\
\text { Switzerland; University } \\
\text { Hospital of Padova, Italy }\end{array}$ & $\begin{array}{l}\text { Major role in the } \\
\text { acquisition of data and } \\
\text { revised the manuscript } \\
\text { for intellectual content }\end{array}$ \\
\hline $\begin{array}{l}\text { Paula Tomas- } \\
\text { Ojer }\end{array}$ & $\begin{array}{l}\text { University Hospital and } \\
\text { University Zurich, } \\
\text { Switzerland }\end{array}$ & $\begin{array}{l}\text { Major role in the } \\
\text { acquisition of data }\end{array}$ \\
& &
\end{tabular}

Appendix (continued)

\begin{tabular}{|c|c|c|}
\hline Name & Location & Contribution \\
\hline $\begin{array}{l}\text { Thorsten } \\
\text { Hornemann, PhD }\end{array}$ & $\begin{array}{l}\text { University Hospital and } \\
\text { University Zurich, } \\
\text { Switzerland }\end{array}$ & $\begin{array}{l}\text { Acquisition of data and } \\
\text { revised the manuscript } \\
\text { for intellectual content }\end{array}$ \\
\hline $\begin{array}{l}\text { Andreas } \\
\text { Lutterotti, MD }\end{array}$ & $\begin{array}{l}\text { University Hospital and } \\
\text { University Zurich, } \\
\text { Switzerland }\end{array}$ & $\begin{array}{l}\text { Revised the manuscript } \\
\text { for intellectual content }\end{array}$ \\
\hline $\begin{array}{l}\text { Ilijas Jelcic, MD, } \\
\text { PhD }\end{array}$ & $\begin{array}{l}\text { University Hospital and } \\
\text { University Zurich, } \\
\text { Switzerland }\end{array}$ & $\begin{array}{l}\text { Revised the manuscript } \\
\text { for intellectual content }\end{array}$ \\
\hline Mario Ziegler & $\begin{array}{l}\text { University Hospital and } \\
\text { University Zurich, } \\
\text { Switzerland }\end{array}$ & Acquisition of data \\
\hline $\begin{array}{l}\text { Andreas J. } \\
\text { Hülsmeier, PhD }\end{array}$ & $\begin{array}{l}\text { University Hospital and } \\
\text { University Zurich, } \\
\text { Switzerland }\end{array}$ & $\begin{array}{l}\text { Acquisition of data and } \\
\text { revised the manuscript } \\
\text { for intellectual content }\end{array}$ \\
\hline $\begin{array}{l}\text { Carolina } \\
\text { Cruciani, PhD }\end{array}$ & $\begin{array}{l}\text { University Hospital and } \\
\text { University Zurich, } \\
\text { Switzerland }\end{array}$ & Acquisition of data \\
\hline $\begin{array}{l}\text { Wolfgang Faigle, } \\
\text { PhD }\end{array}$ & $\begin{array}{l}\text { University Hospital and } \\
\text { University Zurich, } \\
\text { Switzerland }\end{array}$ & $\begin{array}{l}\text { Revised the manuscript } \\
\text { for intellectual content }\end{array}$ \\
\hline $\begin{array}{l}\text { Roland Martin, } \\
\text { MD, PhD }\end{array}$ & $\begin{array}{l}\text { University Hospital and } \\
\text { University Zurich, } \\
\text { Switzerland }\end{array}$ & $\begin{array}{l}\text { Interpreted the data and } \\
\text { revised the manuscript } \\
\text { for intellectual content }\end{array}$ \\
\hline $\begin{array}{l}\text { Mireia Sospedra, } \\
\text { PhD }\end{array}$ & $\begin{array}{l}\text { University Hospital and } \\
\text { University Zurich, } \\
\text { Switzerland }\end{array}$ & $\begin{array}{l}\text { Designed and } \\
\text { conceptualized the } \\
\text { study; analyzed the } \\
\text { data; interpreted the } \\
\text { data; and drafted the } \\
\text { manuscript for } \\
\text { intellectual content }\end{array}$ \\
\hline
\end{tabular}

\section{References}

1. Varatharaj A, Galea I. The blood-brain barrier in systemic inflammation. Brain Behav Immun 2017;60:1-12.

2. Takeda S, Sato N, Ikimura K, Nishino H, Rakugi H, Morishita R. Increased bloodbrain barrier vulnerability to systemic inflammation in an Alzheimer disease mouse model. Neurobiol Aging 2013;34:2064-2070.

3. Denes A, Ferenczi S, Kovacs KJ. Systemic inflammatory challenges compromise survival after experimental stroke via augmenting brain inflammation, blood- brain barrier damage and brain oedema independently of infarct size. J Neuroinflammation $2011 ; 8: 164$.

4. Serres S, Anthony DC, Jiang Y, et al. Systemic inflammatory response reactivates immune-mediated lesions in rat brain. J Neurosci 2009;29:4820-4828.

5. Lopez-Ramirez MA, Wu D, Pryce G, et al. MicroRNA-155 negatively affects bloodbrain barrier function during neuroinflammation. FASEB J 2014;28:2551-2565.

6. Elwood E, Lim Z, Naveed H, Galea I. The effect of systemic inflammation on human brain barrier function. Brain Behav Immun 2017;62:35-40.

7. Uher $\mathrm{T}$, Horakova $\mathrm{D}$, Tyblova $\mathrm{M}$, et al. Increased albumin quotient (QAlb) in patients after first clinical event suggestive of multiple sclerosis is associated with development of brain atrophy and greater disability 48 months later. Mult Scler 2016;22:770-781.

8. Kroth J, Ciolac D, Fleischer V, et al. Increased cerebrospinal fluid albumin and immunoglobulin A fractions forecast cortical atrophy and longitudinal functional deterioration in relapsing-remitting multiple sclerosis. Mult Scler 2019;25:338-343.

9. Polman $\mathrm{CH}$, Reingold SC, Banwell B, et al. Diagnostic criteria for multiple sclerosis: 2010 revisions to the McDonald criteria. Ann Neurol 2011;69:292-302.

10. Reiber H, Peter JB. Cerebrospinal fluid analysis: disease-related data patterns and evaluation programs. J Neurol Sci 2001;184:101-122.

11. Reiber H, Teut M, Pohl D, Rostasy KM, Hanefeld F. Paediatric and adult multiple sclerosis: age- related differences and time course of the neuroimmunological response in cerebrospinal fluid. Mult Scler 2009;15:1466-1480.

12. Brodie T, Rothaeusler K, Sospedra M. OMIP-033: a comprehensive single step staining protocol for human T- and B-cell subsets. Cytometry A 2016;89:629-632.

13. Pellegrino RM, Di Veroli A, Valeri A, Goracci L, Cruciani G. LC/MS lipid profiling from human serum: a new method for global lipid extraction. Anal Bioanal Chem 2014;406:7937-7948. 
14. Narvaez-Rivas M, Zhang Q. Comprehensive untargeted lipidomic analysis using coreshell C30 particle column and high field orbitrap mass spectrometer. J Chromatogr A 2016;1440:123-134.

15. Reiber H. Proteins in cerebrospinal fluid and blood: barriers, CSF flow rate and source-related dynamics. Restor Neurol Neurosci 2003;21:79-96.

16. Watts TH. TNF/TNFR family members in costimulation of T cell responses. Annu Rev Immunol 2005;23:23-68.

17. Bergman J, Dring A, Zetterberg H, et al. Neurofilament light in CSF and serum is a sensitive marker for axonal white matter injury in MS. Neurol Neuroimmunol Neuroinflamm 2016;3:e271.

18. Uher T, McComb M, Galkin S, et al. Neurofilament levels are associated with bloodbrain barrier integrity, lymphocyte extravasation, and risk factors following the first demyelinating event in multiple sclerosis. Mult Scler 2020:1352458520912379.

19. Bonneh-Barkay D, Bissel SJ, Kofler J, Starkey A, Wang G, Wiley CA. Astrocyte and macrophage regulation of YKL-40 expression and cellular response in neuroinflammation. Brain Pathol 2012;22:530-546.

20. Gil-Perotin S, Castillo-Villalba J, Cubas-Nunez L, et al. Combined cerebrospinal fluid neurofilament light chain protein and chitinase-3 like-1 levels in defining disease course and prognosis in multiple sclerosis. Front Neurol 2019;10:1008.

21. Sospedra M, Martin R. Immunology of multiple sclerosis. Annu Rev Immunol 2005; 23:683-747.
22. Haorah J, Ramirez SH, Schall K, Smith D, Pandya R, Persidsky Y. Oxidative stress activates protein tyrosine kinase and matrix metalloproteinases leading to blood-brain barrier dysfunction. J Neurochem 2007;101:566-576.

23. Turner RJ, Sharp FR. Implications of MMP9 for blood brain barrier disruption and hemorrhagic transformation following ischemic stroke. Front Cell Neurosci 2016;10:56.

24. Oreja-Guevara C, Ramos-Cejudo J, Aroeira LS, Chamorro B, Diez-Tejedor E. TH1/ $\mathrm{TH} 2$ cytokine profile in relapsing-remitting multiple sclerosis patients treated with glatiramer acetate or natalizumab. BMC Neurol 2012;12:95

25. Bluestone JA. New perspectives of CD28-B7-mediated T cell costimulation. Immunity 1995;2:555-559.

26. Markovic-Plese S, Cortese I, Wandinger KP, McFarland HF, Martin R. CD4+CD28costimulation- independent $T$ cells in multiple sclerosis. J Clin Invest 2001;108:1185-1194.

27. Karsai G, Lone M, Kutalik Z, et al. FADS3 is a delta $14 \mathrm{z}$ sphingoid base desaturase that contributes to gender differences in the human plasma sphingolipidome. J Biol Chem 2020;295:1889-1897.

28. Pieragostino D, Cicalini I, Lanuti P, et al. Enhanced release of acid sphingomyelinaseenriched exosomes generates a lipidomics signature in CSF of Multiple Sclerosis patients. Sci Rep 2018;8:3071.

29. Becker KA, Halmer R, Davies L, et al. Blockade of experimental multiple sclerosis by inhibition of the acid sphingomyelinase/ceramide system. Neurosignals 2017;25: $88-97$ 


\title{
Neurology \\ Neuroimmunology \& Neuroinflammation
}

\author{
Altered CSF Albumin Quotient Links Peripheral Inflammation and Brain Damage in \\ MS \\ Marco Puthenparampil, Paula Tomas-Ojer, Thorsten Hornemann, et al. \\ Neurol Neuroimmunol Neuroinflamm 2021;8; \\ DOI 10.1212/NXI.0000000000000951
}

This information is current as of March 1, 2021

\section{Updated Information \& \\ Services}

References

Citations

Subspecialty Collections

Permissions \& Licensing

Reprints including high resolution figures, can be found at:

http://nn.neurology.org/content/8/2/e951.full.html

This article cites 28 articles, 3 of which you can access for free at: http://nn.neurology.org/content/8/2/e951.full.html\#\#ref-list-1

This article has been cited by 3 HighWire-hosted articles: http://nn.neurology.org/content/8/2/e951.full.html\#\#otherarticles

This article, along with others on similar topics, appears in the following collection(s):

Autoimmune diseases

http://nn.neurology.org//cgi/collection/autoimmune_diseases Multiple sclerosis

http://nn.neurology.org//cgi/collection/multiple_sclerosis

Information about reproducing this article in parts (figures,tables) or in its entirety can be found online at:

http://nn.neurology.org/misc/about.xhtml\#permissions

Information about ordering reprints can be found online:

http://nn.neurology.org/misc/addir.xhtml\#reprintsus

Neurol Neuroimmunol Neuroinflamm is an official journal of the American Academy of Neurology.

Published since April 2014, it is an open-access, online-only, continuous publication journal. Copyright

Copyright (C) 2021 The Author(s). Published by Wolters Kluwer Health, Inc. on behalf of the American

Academy of Neurology.. All rights reserved. Online ISSN: 2332-7812.

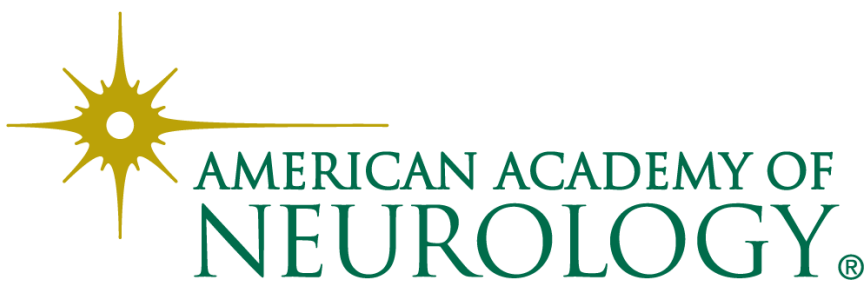

